\title{
Comparison of the effect of fixed and variable taper on the volume of obturation material
}

SADJ February 2019, Vol. 74 No. 1 p 8 - p12

AOA Hassan ${ }^{1}$, IE Munshi², S Tootla ${ }^{3}$

\section{INTRODUCTION}

Cleaning and shaping of the root canal system are critical steps in endodontic procedures to create adequate space to enable irrigation solutions to reach areas that are inaccessible to instrumentation, to thereby reduce irritants and to facilitate the obturation of the root canal space..$^{1,2}$ Inadequate management of the root canal system may result in uninstrumented areas not being sealed by the obturating material. ${ }^{3}$ Appropriate shaping of the root canal creates an apical resistance which reduces extrusion of the filling material beyond the apical foramen and creates a wider coronal third which will facilitate movement of irrigation solutions. ${ }^{4}$

Shaping the root canal system can follow three different configurations. Traditionally, the root canal was prepared to the full working length. ${ }^{5}$ The flaring (fixed tapered preparation) technique was advocated in 1974 to improve the prepared shape of the root canal system. ${ }^{4}$ In 2000 , Buchanan ${ }^{6}$ introduced the concept of variable tapered root canal preparation, where the diameter of the root canal increases progressively towards the coronal third.

Concomitantly, endodontic instruments have been through several eras of development, one of the most significant being the introduction, and ongoing modification of, the Nickel Titanium (NiTi) rotary file. ${ }^{7}$ According to Haapasalso and Shen $(2013)^{8}$ the first generation design was introduced in 1992 by McSpadden ${ }^{7}$ who developed the $2 \%$ tapered file. Subsequently, $4 \%$ and $6 \%$ tapered files were introduced, the cutting performance was improved and the metallurgy was enhanced. A reciprocating file was introduced in 2008 by Yared, which lead to the single file concept, and both continuous rotation and reciprocating motions are now used. ${ }^{8}$

\section{Author affiliations:}

1. Almeqdad Hassan: BDS (International University of Africa, Sudan), MSCDENT (Endodontics), WITS University), Department of Paediatric and Restorative Dentistry, School of Oral Health Science, Faculty of Health Sciences, University of the Witwatersrand, Johannesburg, South Africa.

2. Ismail Munshi: BSC, BChD (University of Western Cape), MDent (WITS University), Department of Oral Rehabilitation, School of Oral Health Sciences, Faculty of Health Sciences, University of the Witwatersrand, Johannesburg, South Africa.

3. Saidah Tootla: BChD (University of Western Cape ), MSC, MM (WITS University), Department of Paediatric and Restorative Dentistry, School of Oral Health Science, Faculty of Health Sciences, University of the Witwatersrand, Johannesburg, South Africa.

Corresponding author: Almeqdad Hassan

Department of Paediatric and Restorative Dentistry, School of Oral Health Science, Faculty of Health Sciences, 7 York Road, Parktown 2193, South Africa. Tel: +27 (0)81 8100469 Email: meq.osman@gmail.com

\section{ACRONYMS \\ GP: \\ Gutta Percha \\ NiTi: \\ OS group: \\ Nickel Titanium \\ VC: \\ VO: \\ Fixed Taper \\ WO group: \\ 3-D volume of the canal \\ 3-D volume of obturation}

NiTi rotary files have either fixed or variable tapering. Fixed tapered files have a constant angle of increasing diameter along the active portion of the file, while variable-tapered files have different tapers of increasing and decreasing angles along that portion of the file. Variable-tapered files have been shown to result in greater straightening and transporting of the outer aspect of the apical curvature when compared with the effect of the fixed-tapered file. On the mid-root curvature, the variable-tapered file was better in preserving tooth structure than were fixed-tapered endodontic files. ${ }^{9-11}$

Root canal obturation refers to forming a fluid-tight seal to completely fill the root canal system with nonirritating material from the apical foramen to the orifice level, preventing the apical, lateral and coronal microleakage that is known to affect the long-term success of endodontic treatment. ${ }^{12}$ It has been shown that both the quality of both the obturating material and of the coronal restoration relate significantly to the status of the periodontium, determining root canal success or failure. ${ }^{13-15}$

While many obturation materials have been introduced, Gutta Percha (GP) remains the most widely used. A number of techniques to facilitate GP placement and to improve the quality of obturation have been developed; recent examples are Thermafill and GuttaCore (Dentsply/ Sirona, Germany). Studies have shown that obturating systems frequently present with voids, which become colonized by bacteria and are therefore associated with microleakage. ${ }^{16}$ Therefore, the quality of the obturation seal is of paramount importance.

Another factor affecting the quality of obturation is the position of the termination of the root canal filling. The most desirable length has not been exactly determined ${ }^{12}$ and is controversial, but it is accepted that extrusion of the filling material is associated with failure ${ }^{17}$ and a reduction in healing rate. ${ }^{18}$ Histologically, the minor apical constriction located $0.5 \mathrm{~mm}$ from the external surface determines the apical limit of the root canal and thus both instrumentation and obturation should be limited to this area. ${ }^{19}$ 
Previous studies have shown the effect of file taper on the preparation of the root canal system ${ }^{9-11}$ and the effect of the taper on the extrusion of obturating materials beyond the apical foramen. ${ }^{20}$ No studies have been found relating the effect of the geometry of the taper (fixed versus variable) to the quality of obturation in terms of the presence of voids, or the amount of extrusion of GP. Therefore this in vitro study set out to evaluate these variables; the null hypothesis was that there would be no difference in the quality of root canal obturation when canals are prepared with either fixed or variable tapers.

\section{MATERIAL AND METHODS}

Ethical approval for the use of extracted teeth was granted by the University Human Research Ethics Committee (W-CJ-160615-1). Permanent sound single-rooted anterior and premolar teeth having roots with a curvature less than $25^{\circ}$ were included. C-shaped or oval canals and teeth with canal diameters greater than size 25 GuttaCore size verifier were excluded. To detect an effect size of $d=0.75 \mu \mathrm{m}^{3}$, at $80 \%$ power and at a $5 \%$ significance level, a sample size of 29 teeth per group was required. ${ }^{21}$ To allow for any errors in method, 32 teeth per group were used.

After selection, each tooth was cleaned from any attached bone or tissue using a number 15 scalpel and high speed handpiece with a long diamond bur (Mani, Inc, Japan). Thereafter all the teeth were stored in formalin $(\mathrm{pH} 7.25)$ at room temperature for approximately two months. Before preparation, each tooth was mounted in an acrylic resin block of size $3 \times 2 \times 3 \mathrm{~cm}$ (Sure Acrylic, packaged for Confi-Dent Agencies, SA) to facilitate handling.

The selected teeth were randomly divided into two groups: OS group: 32 teeth were prepared with a fixed taper (One Shape file, MicroMega, France) and the WO group: 32 teeth were prepared with a variable taper (Wave One Gold primary file, Dentsply/Sirona, Switzerland). The samples were standardized by grinding the occlusal table to create a length of $15 \mathrm{~mm}$ for all teeth. All the procedures (preparation and obturation) were performed by a single operator at room temperature using a dental operating microscope (Carl Zeiss Surgical GmbH, Germany) at $5.1 \times$ magnification .

Patency was established and a glide path was prepared for each tooth using sizes 8 and $10 \mathrm{~K}$ files (MicroMega, France) as required. One $G$ (MicroMega, France) and Proglider (Dentsply/Sirona, Switzerland) files were used for rotary glide path preparation for OS and WO groups respectively, following the manufacturers' instructions for speed and torque. The working length was established once a size $10 \mathrm{~K}$ file (MicroMega, France) appeared through the apical foramen. It was withdrawn by $0.5 \mathrm{~mm}$ to establish the working length.

The canals were then prepared using the One Shape file for the OS group and the Wave One Gold primary file for the WO group. The mechanical preparations were performed as per the manufacturers' instructions, including single file use. All teeth prepared with Wave One Gold files were completed with the primary file only. An X Smart plus motor (Dentsply Sirona, Switzerland) was used in both rotary glide path preparation and mechanical preparation for both the Wave One gold and One Shape file systems. Figure 1 shows the 3-D volume of typical preparations of the canals.

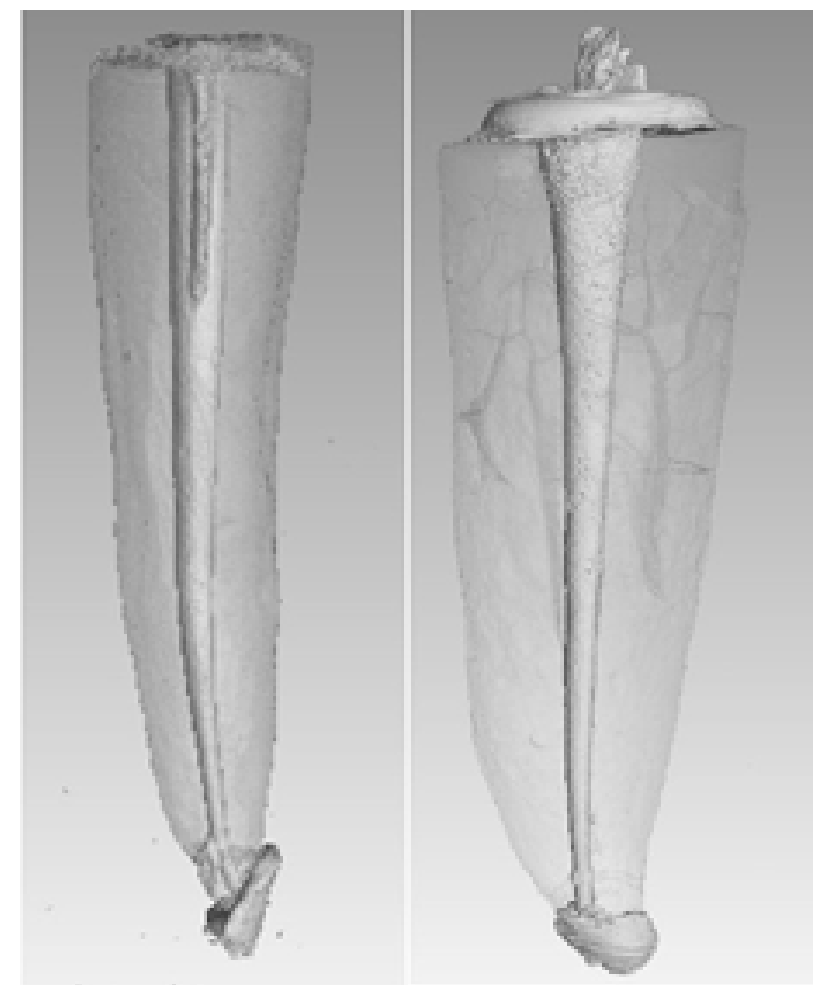

Figure 1. A 3-D volume of typical preparations of the canals, with the fixed tapered preparation on the left, and the variable tapered preparation on the right.

The irrigation solutions were standardized for both groups as follows: irrigation during instrumentation was done with $5 \mathrm{ml}$ of $6 \% \mathrm{NaOCl}$ with a 29 gauge/17mm NaviTip needle (Ultradent, USA); the final rinse protocol was done using $2 \mathrm{ml}$ of $6 \% \mathrm{NaOCl}$ solution for three minutes followed by $1 \mathrm{ml} 17 \%$ EDTA solution for one minute. While the 6\% $\mathrm{NaOCl}$ filled the canal, it was manually agitated 50 to 60 times using a GP master apical cone.

Before obturation, each canal was thoroughly dried using paper points (Dentsply/Sirona, Switzerland). The GuttaCore obturator system was used according to the manufacturer's instructions. A GuttaCore size 25 verifier was used to confirm the apical fitting. The sealer (AH Plus sealer, Dentsply/Sirona, Switzerland) was wiped on the canal wall to the full working length, using a size 25 paper point. Sealer excess was removed with a smaller paper point.

The GuttaCore obturator was heated in a Thermaprep 2 oven (Dentsply/Sirona, Switzerland) and then slowly inserted in a gentle continuous motion (for 6 to 7 seconds) to the determined working length. Two minutes after obturation the handle of the GuttaCore obturator was removed by bending the handle to the side several times until it was severed.

After obturation, the teeth were stored in a digital incubator (IncoTherm, Labotec, South Africa) at $37^{\circ} \mathrm{C}$ and $100 \%$ humidity for five days to facilitate complete setting of the sealer prior to microCT $(\mu \mathrm{CT})$ scanning (Nikon Metrology XTH 225/320 LC Micro-CT scanner, Germany). 
A software programme (Avizo 7.0, VGStudio MAX 3.0) was manipulated to establish a straight vertical axis of the tooth and to distinguish the images of tooth structure from the obturation and voids. Only the apical $12 \mathrm{~mm}$ of each tooth was included for analysis, while the rest of the coronal part of the tooth image was removed.

The 3-D volume of the canal (VC) and the volume of obturation (VO) were measured in $\mu \mathrm{m}^{3}$ and then the 3-D difference (D) was calculated by deducting the VO from the VC. The percentage difference (D\%) was calculated using the following equation: VC - VO/VC * 100. The volume of any extruded GP (without sealer) beyond the apical foramen, was measured in $\mu \mathrm{m}^{3}$. Fig. 2 shows a sagittal view of the extruded GP, and Fig. 3 shows a 3-D view.

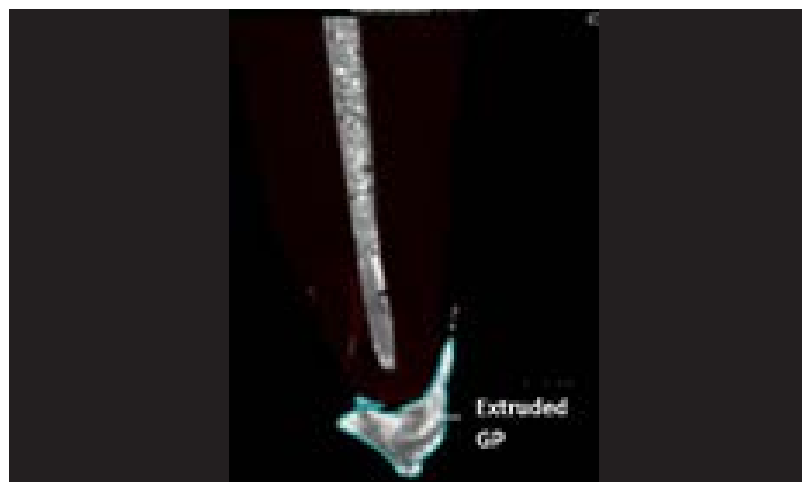

Figure 2. Sagittal view of extruded GP without sealer.

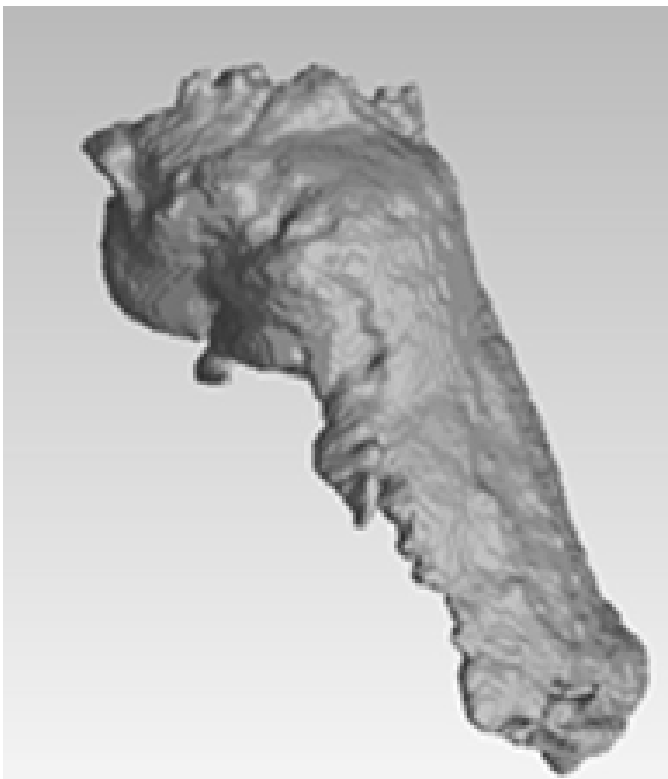

Figure 3. Three-dimensional view of extruded GP.
Data analysis was performed using SAS 9.4 for Windows (SAS Institute Inc; Cary, North Carolina, United States of America). The Wilcoxon rank sum test was applied to assess the relationship between each outcome and the OS and WO groups (the data did not meet the assumptions of an independent samples t-test). The strength of any associations was measured by $r$, using the following scale $\mathrm{d}$ : $\geq 0.80$ e (large effect), 0.50 to 0.79 (moderate effect), 0.20 to 0.49 (small effect) and $\leq 0.20$ (near zero effect).

\section{RESULTS}

The univariate statistics for all the variables are shown in Table 1. All variables showed statistically significant differences between the two groups, although the effect sizes were small (Table 2).

\begin{tabular}{|ccc|}
\hline $\begin{array}{c}\text { Table 2. Statistically significant differences and effect sizes. } \\
\text { Variable }\end{array}$ & $\begin{array}{c}\text { p-value for } \\
\text { between-group test }\end{array}$ & $\begin{array}{c}\text { Effect size } \\
(\mathbf{r})\end{array}$ \\
\hline D & 0.0034 & 0.38 \\
D\% & 0.0041 & 0.38 \\
E & 0.0013 & 0.42 \\
\hline
\end{tabular}

No obturated canal obtained a $100 \%$ seal and it is therefore concluded that all must have contained voids. The WO group resulted in a greater volume of obturated GP (represented by the difference in volume, D, and the percentage differences, D\%) and a significantly smaller amount of extruded GP (Fig. 4). However, the effect sizes of all the differences were small.

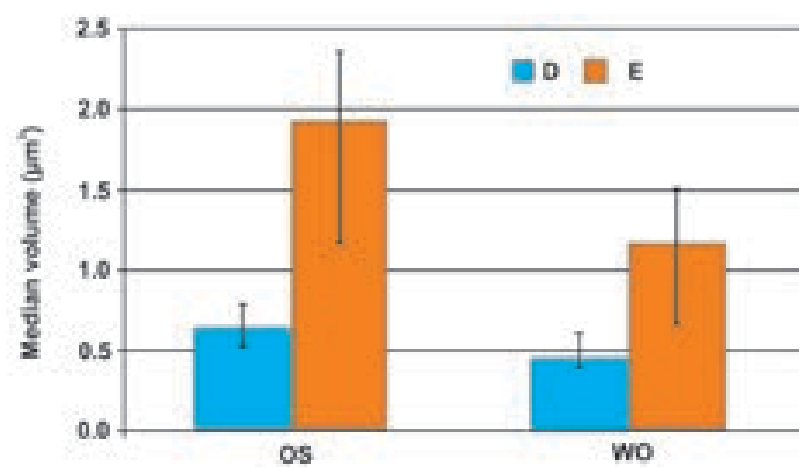

Figure 4. The median volume difference (D) and volume of extruded obturation $(E)$. The error bars denote the inter-quartile range.

The strength of association between the tapered angle of the root canal and the volume of extruded GP was tested. The analysis of the result showed that the correlation was small $(r=0.42)$.

Table 1. Univariate statistics. SD: standard deviation; OS: OneShape group; WO: WaveOne group; D: difference in volume between canal preparation and obturation $\left(\mu \mathrm{m}^{3}\right)$; D\%: percentage difference in volume between canal preparation and obturation; E: volume of extruded material $\left(\mu \mathrm{m}^{3}\right)$.

\begin{tabular}{|c|c|c|c|c|c|c|}
\hline Group & Variable & Mean & SD & Median & $\begin{array}{c}\text { Inter-quartile } \\
\text { range }\end{array}$ & $\begin{array}{l}\text { Range } \\
\text { (min-max) }\end{array}$ \\
\hline \multirow[t]{3}{*}{ OS $(n=32)$} & $\mathrm{D}(\mu \mathrm{m} 3)$ & 0.68 & 0.22 & 0.65 & $0.52-0.79$ & $0.26-1.28$ \\
\hline & $\mathrm{D} \%$ & 10.6 & 2.2 & 10.6 & $9.5-12.4$ & $5.1-13.8$ \\
\hline & $E(\mu m 3)$ & 1.94 & 0.97 & 1.92 & $1.16-2.36$ & $0.42-4.02$ \\
\hline \multirow[t]{3}{*}{ WO $(n=32)$} & $D(\mu m 3)$ & 0.54 & 0.22 & 0.45 & $0.39-0.61$ & $0.32-1.19$ \\
\hline & $\mathrm{D} \%$ & 9.2 & 3.6 & 8.5 & $6.4-10.7$ & $5.7-24.2$ \\
\hline & $E(\mu m 3)$ & 1.16 & 0.68 & 1.16 & $0.66-1.51$ & 0.00-2.99 \\
\hline
\end{tabular}




\section{DISCUSSION}

Clinically, voids in root fillings are difficult to detect because conventional $\mathrm{x}$-rays give a limited two-dimensional view of the tooth. ${ }^{22}$ Root canal obturation from a conventional radiograph is regarded as acceptable when the density is uniform along the canal from the orifice level to the terminus and compatible with the canal walls. ${ }^{23}$

In vitro, many methods (dye penetration, fluid transport, etc.) have been used to investigate the sealing ability of root filling techniques and materials. ${ }^{24,25}$ However, al had the limitation of measuring voids by analysis of sectioned roots and digital imaging software. Those approaches may not be accurate enough because some filling material might be lost in the process. ${ }^{25}$

However, because of the inaccuracy and lack of standardisation of the previous methods, researchers have moved to a non-destructive, reproducible and more accurate method of evaluating the quality of root filling materials using $\mu \mathrm{CT}$. The value of the use of $\mu \mathrm{CT}$ has been demonstrated in previous studies. ${ }^{26,27}$ It is non-destructive, non-invasive and gives a 3-D visualisation of the defect and continuity of the defect in the root filling material.

This study analysed the volume of obturation of root canals as an indication of the effectiveness of canal preparation with two different canal preparation geometries, namely fixed taper (obtained using the OneShape system) and variable tapered preparations (using the WaveOne system).

The results showed that voids were present within the obturation as there were no canals that had a 100\% seal. This is in accord with other studies. ${ }^{28,29}$ The variable tapered canals had a significantly better volume of obturation and significantly less extrusion of material. However, the effect sizes were small. An earlier study by Allison et al (1979) showed a strong correlation between canal taper and the quality of obturation: a flared (tapered) preparation had better obturation than did the standardized technique. However, those authors used cold lateral condensation rather than the flowable obturation technique used in this study, which is not dependent on any condensing instrument.

A study comparing three different tapered preparations $(4 \%, 6 \%$ and $8 \%)$ on the quality of thermoplastic obturation found that the larger the taper the better the obturation. There was no significant difference between $6 \%$ taper and $8 \%$ taper but both were significantly better than the $4 \%$ taper, ${ }^{30}$ implying improvements in obturation with increasing taper. The current study, however, kept the taper relatively constant, but varied the shape geometry, so that when the apical taper is large enough, greater than $6 \%$, the geometrical shapes of fixed and variable tapers have a small impact on the quality of the obturation.

A possible explanation for the statistically significant difference between the OS and WO groups could be related to the volume of the canals created by each file system. Shaping canals with the One Shape file resulted in a larger volume of the prepared root canal $\left(230.057 \mu^{3}\right)$ when compared with the WO group in which the total volume of the prepared canal was $187.1 \mu^{3}$.
With respect to the extrusion of GP beyond the apical foramen, this is a common finding in endodontics. ${ }^{31}$ The incidence of extrusion of thermoplastisized GP has been shown to be 50\% compared with 20\% for cold lateral obturation, ${ }^{32}$ and Thermafil obturation had more extruded GP than other obturation techniques. ${ }^{33,34}$ Although flowable GP (chemical or heated GP) is shown to have a better quality of obturation than cold obturation, ${ }^{35,36}$ a meta-analysis indicated that it was associated with more extrusion. ${ }^{37}$

In the current study, the fixed taper resulted in a higher volume of extruded GP than in the variable taper preparation. Extrusion of GP was detected in all the specimens except one. These findings support the statement by Buchanan $(2000)^{6}$ that variably tapered preparations resulted in a smaller apical diameter thus reducing the extruded GP. On the other hand, it has been shown that extrusion can also relate to the filling material, when it was found that Thermafil plus but not Realseal was affected by preparation taper and resulted in significantly higher extrusion. ${ }^{38}$

It has also been shown that the insertion rate affects the overfill or underfill of the obturation. An insertion rate of thermoplastic GP that produced fewer voids also produced undesirable extrusion. ${ }^{39}$ In the current study, only the GuttaCore obturation system was used, so it is possible that the extrusion may have been due to the rate of insertion.

A possible limitation of the study was that only one obturation material was used, and one sealant, and a single obturation technique, but this was to standardise the obturation as a fixed effect.

Although irrigation plays an integral role in reaching inaccessible areas for instrumentation, disintegrating soft tissue, removing the smear layer and disinfecting the canal, ${ }^{40,41}$ it has been shown that the root canal system should be prepared up to size 30 at least for irrigation to reach the apical third. ${ }^{2}$ However, enlargement of the root canal system during shaping procedures can increase the risk of root fracture. For example, root fracture is a common finding in maxillary premolars because of the small mesiodistal dimension of their roots. ${ }^{42}$

Furthermore, cracks in radicular dentine have been found to be associated with endodontic retreatment irrespective of whether rotary or hand file instruments were used. ${ }^{43}$ Caution should therefore always be exercised to avoid the undue enlargement of root canals.

\section{CONCLUSIONS}

Both systems studied, Wave One Gold and One Shape files, could be used to prepare root canals adequately for obturation. This study has shown that when the apical taper is large enough, 6\% - 8\%, the geometrical shapes of fixed and variable tapers have a small impact on the quality of the obturation. The variable tapered preparation showed slightly less GP extrusion than did the fixed tapered preparation. The value of $\mu \mathrm{CT}$ as an accurate research tool in Endodontics has been re-emphasized. 


\section{References}

1. Walton RE. Current concepts of canal preparation. Dent Clin North Am. 1992; 36: 309-26.

2. Khademi A, Yazdizadeh M, Feizianfard M. Determination of the minimum instrumentation size for penetration of irrigants to the apical third of root canal systems. J Endo. 2006; 32: 417-20.

3. Wu MK, Wesselink PR. Endodontic leakage studies reconsidered. Part 1. Methodology, application and relevance. Int Endod J. 1993; 26: 37-43.

4. Schilder $\mathrm{H}$. Cleaning and shaping the root canal. Dent Clin North Am. 1974; 18: 269-96.

5. Allison DA, Weber CR, Walton RE. The influence of the method of canal preparation on the quality of apical and coronal obturation. J Endod. 1979; 5: 298-304.

6. Buchanan LS. The standardized-taper root canal preparation - Part 1. Concepts for variably tapered shaping instruments. Int Endod J. 2000; 33: 516-29.

7. McSpadden, JT. Endodontic instrument. US Patent US5104316A. 1992

8. Haapasalo M, Shen Y. Evolution of nickel-titanium instruments: from past to future. Endodontic Topics. 2013; 29: 3-17.

9. Bergmans L, Van Cleynenbreugel J, Beullens M, Wevers M, Van Meerbeek B, Lambrechts P. Progressive versus constant tapered shaft design using NiTi rotary instruments. Int Endod J. 2003; 36: 288-95

10. Yang GB, Zhou XD, Zhang $H$, Wu HK Shaping ability of progressive versus constant taper instruments in simulated root canals. Int Endod J. 2006; 39: 791-9.

11. Yang GB, Zhou XD, Zheng YL, Zhang H, Shu Y, Wu HK. Shaping ability of progressive versus constant taper instruments in curved root canals of extracted teeth. Int Endod J. 2007; 40: 707-14.

12. Sjogren U, Hagglund B, Sundqvist G, Wing K. Factors affecting the long-term results of endodontic treatment. J Endod. 1990; 16: 498-504

13. Kerekes K, Tronstad L. Long-term results of endodontic treatment performed with a standardized technique. J Endod. 1979; 5: 83-90.

14. Ray HA, Trope M. Periapical status of endodontically treated teeth in relation to the technical quality of the root filling and the coronal restoration. Int Endod J. 1995; 28: 12-8.

15. Ng YL, Mann V, Rahbaran S, Lewsey J, Gulabivala K. Outcome of primary root canal treatment: systematic review of the literature - Part 2. Influence of clinical factors. Int Endod J. 2008; 41: 6-31.

16. Gandolfi MG1, Parrilli AP, Fini M, Prati C, Dummer PM. 3D micro-CT analysis of the interface voids associated with Thermafil root fillings used with $\mathrm{AH}$ Plus or a flowable MTA sealer. Int Endod J. 2013; 46: 253-63.

17. Siqueira JF Jr, Rôças IN, Ricucci D, Hülsmann M. Causes and management of post-treatment apical periodontitis. Br Dent J. 2014; 216: 305-12

18. Ricucci D, Langeland K. Apical limit of root canal instrumentation and obturation. Part 2. A histological study. Int Endod J. 1998; 31: 394-409.

19. Ricucci D. Apical limit of root canal instrumentation and obturation. Part 1. Literature review. Int Endod J. 1998; 31: 384-93.

20. Whitten RB, Levitan ME. The effect of canal preparation on fill length in straight root canals obturated with GuttaCore. J Endod. 2015; 41: 155-8.

21. Faul F, Erdfelder E, Lang AG. Buchner A. Power G. A flexible statistical power analysis program for the social, behavioral, and biomedical sciences. Behav Res Methods. 2007; 39: 175-91.

22. Nair MK, Nair UP. Digital and advanced imaging in endodontics: a review. J Endod. 2007; 33: 1-6.

23. Lupi-Pegurier L, Bertrand MF, Muller-Bolla M, Rocca JP, Bolla M. Periapical status, prevalence and quality of endodontic treatment in an adult French population. Int Endod J. 2002; 35: $690-7$.
24. Tagger M, Tamse A, Katz A, Korzen BH. Evaluation of the apical seal produced by a hybrid root canal filling method, combining lateral condensation and thermatic compaction. J Endod. 1984; 10: 299-303.

25. Jarrett IS, Marx D, Covey D, Karmazin M, Lavin M, Gound T. Percentage of canals filled in apical cross sections - an in vitro study of seven obturation techniques. Int Endod J. 2004; 37: 392-8.

26. Oi T, Saka H, Ide Y. Three-dimensional observation of pulp cavities in the maxillary first premolar tooth using micro-CT. Int Endod J. 2004; 37: 46-51.

27. Verma P, Love RM. A micro CT study of the mesiobuccal root canal morphology of the maxillary first molar tooth. Int Endod J. 2011; 44: 210-7.

28. Anbu R1, Nandini S, Velmurugan N. Volumetric analysis of root fillings using spiral computed tomography: an in vitro study. Int Endod J. 2010; 43: 64-8.

29. Keles A, Alcin H, Kamalak A, Versiani MA. Micro-CT evaluation of root filling quality in oval-shaped canals. Int Endod J. 2014; 47: 1177-84.

30. Zogheib C, Naaman A, Medioni E, Arbab-Chirani R. Influence of apical taper on the quality of thermoplasticized root fillings assessed by micro-computed tomography. Clin Oral Investig. 2012; 16: 1493-8.

31. Abarca AM, Bustos A, Navia M. A comparison of apical sealing and extrusion between Thermafil and lateral condensation techniques. J Endod. 2001; 27: 670-2.

32. Mann SR, McWalter GM. Evaluation of apical seal and placement control in straight and curved canals obturated by laterally condensed and thermoplasticized gutta-percha. J Endod. 1987; 13: 10-17.

33. Gutman JL, Saunders WP, Saunders EM, Nguyen L. An assessment of the plastic Thermafil obturation technique. Part 1. Radiographic evaluation of adaptation and placement. Int Endod J. 1993; 26: 173-8,

34. Clark DS1, EIDeeb ME. Apical sealing ability of metal versus plastic carrier Thermafil obturators. J Endod. 1993; 19: 4-9.

35. Boussetta F, Bal S, Romeas A, Boivin G, Magloire H, Farge $P$. In vitro evaluation of apical microleakage following canal filling with a coated carrier system compared with lateral and thermomechanical Gutta-Percha condensation techniques. Int Endod J. 2003; 36: 367-71.

36. Weis MV, Parashos P, Messer HH. Effect of obturation technique on sealer cement thickness and dentinal tubule penetration. Int Endod J. 2004; 37: 653-63.

37. Peng L, Ye L, Tan H, Zhou X. Outcome of root canal obturation by warm gutta-percha versus cold lateral condensation: a meta-analysis. J Endod. 2007; 33: 106-9.

38. Heeren TJ, Levitan ME. Effect of canal preparation on fill length in straight root canals obturated with RealSeal 1 and Thermafil Plus. J Endod. 2012; 38: 1380-2.

39. Levitan ME, Himel VT, Luckey JB. The effect of insertion rates on fill length and adaptation of a thermoplasticized guttapercha technique. J Endod. 2003; 29: 505-8.

40. Caron, G, Nham, K, Bronnec, F, Machtou, P. Effectiveness of different final irrigant activation protocols on smear layer removal in curved canals. J Endod. 2010; 36: 1361-6.

41. Azim A. A, Aksel H, Zhuang T, Mashtare T, Babu J.P, Huang G.T Efficacy of four irrigation protocols in killing bacteria colonized in dentinal tubules examined by a novel confocal laser scanning microscope analysis. J Endod. 2016; 42: 928-34.

42. Santos AFV, Tanaka CB, Lima RG et al. Vertical root fracture in upper premolars with endodontic posts: finite element analysis. Endod. 2009; 35: 117-20.

43. Shemesh H, Roeleveld AC, Wesselink PR, Wu MK. Damage to root dentin during retreatment procedures. J Endod. 2011; 37: $63-6$ 